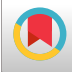

\title{
Requirements of Using the Blended Educational System from the Viewpoints of the Faculty Members
}

\author{
Mahdi Mahmodi, 1," and Maryam Jalali Moghadam² \\ ${ }^{1}$ Educational Sciences and Psychology Department, Payam Noor University, Tehran, Iran \\ ${ }^{2}$ Literatureon Foreignlanguages Department, Payam Noor University, Tehran, Iran \\ "Corresponding author: Mahdi Mahmodi, Educational Sciences and Psychology Department, Payam Noor University, Tehran, Iran. Tel: +98-2122455076, Fax: +98-2122441791, \\ E-mail: mahmodi@te.pnu.ac.ir
}

Received 2017 April 20; Revised 2017 July 31; Accepted 2017 August 28.

\begin{abstract}
Background: Implication of blended learning could compensate both the limitations of time and geographic distance presented in traditional classroom methods and deficiencies of class interaction and learners support that are peculiar to e-learning methods. To this aim, the present study was designed to examine and analyze the requirements for blended learning implications in higher education from faculty members' point of view.

Methods: The study was conducted during spring of 2016 at the Semnan province Payam Noor branches. Participants in this study were 70 academic members of Semnan Payam Noor University, who were randomly selected by the Krejcie and Morgan formula from 85 faculty members. The data collection instrument was a newly developed questionnaire, the validity of which was determined by seeking views of 15 specialists in e-learning using the Delphi method. The reliability of the questionnaire was estimated through calculating internal consistency of items $(\alpha=0.95)$. To analyze factors underlying specified requirements by the questionnaire, a factor analysis was conducted by the SPSS V.18 software.

Results: Factor analysis of academic members' views resulted in 5 factors constituting “infrastructure, political, professional, organizational, and instructional" requirements. From academic members' point of view, infrastructure requirements with nine loaded items were the most preliminary considerations for blended learning implication and accounted for $49.24 \%$ of the total variance. The second factor, political requirements, with six loaded items accounted for $7.75 \%$ of total variance. The third factor, professional requirements, with five loaded items, accounted for 6.29 of the total variance. The fourth factor, organizational requirements, with three loaded items and the fifth factor, instructional requirements, with two loaded items accounted for $4.61 \%$ and $4.34 \%$ of the total variance, respectively.

Conclusions: The findings showed that successful implementation of blended learning would result from considerations, such as "allocation of sufficient funds" and "provision of necessary software/hardware facilities" for blended learning in policies of universities and higher education institutions.
\end{abstract}

Keywords: Blended Learning Implication, Blended Learning Requirements, Academic Members' Views

\section{Background}

As a new subject of interest in the field of instruction and learning, it could be said that blended learning refers to the combination of traditional classroom learning features, such as convenience, interaction opportunities, cooperation, and socialization with various activities and events of e-learning and updated facilities of online environment.

Blended learning, which is also called hybrid learning, has a different meaning for different people and has various definitions (1). Garrison and Vaughan (2) defined blended learning as a thoughtful combination of e-learning and face-to-face learning in a way that learners could choose activities based on their pace, level, and style of learning. In this method, learners could be more autonomous and confident in their learning. Moreover, they can participate in real classes and improve their social skills (3). For Valitan (4), blended learning is a type of learning in which event-based activities, such as face to face classroom activities, live e-learning, and self-placed learning are combined. Akkoyunlu and Soylu (5) and Gould
(6) argued that in blended learning, learners enjoy advantages of e-learning as well as face-to-face learning. By adding aspects of teaching and learning styles, Procter (7) developed a relatively more comprehensive definition of blended learning. To him, blended learning is an effective combination of various delivery modes, teaching methods, and learning styles. Since in this definition, aspects of teaching and learning styles are considered, it is a more comprehensive definition of blended learning. However, the most encompassing definition of blended learning belongs to Driscoll (8). She believed that blended learning refers to four different concepts:

1- To combine or mix modes of web-based technology (e.g. live virtual classroom, self-paced instruction, collaborative learning, streaming video, audio, and text) to accomplish an educational goal.

2- To combine various pedagogical approaches (e.g. constructivism, behaviorism, and cognitivist) to produce an optional learning outcome with or without instructional technology.

3- To combine any form of instructional technology (e.g. videotape, CD-ROM, web-based training, and film)

Copyright (c) 2017, Interdisciplinary Journal of Virtual Learning in Medical Sciences. This is an open-access article distributed under the terms of the Creative Commons Attribution-NonCommercial 4.0 International License (http://creativecommons.org/licenses/by-nc/4.0/) which permits copy and redistribute the material just in noncommercial usages, provided the original work is properly cited. 
with face-to-face instructor-led training.

4- To mix or combine instructional technology with actual job tasks in order to create a harmonious effect of learning and working.

Today, pioneer supporters of e-learning, reject "online learning against face to face learning" and believe in "blended learning" as the third solution, which would be more successful (9).

Blended learning is a mixture of pedagogical approaches that combines the effectiveness and the socialization opportunities of the classroom with technological enhancements of online learning (10). Within this mix, is a paradigm change, in which the emphasis shifts from teaching to learning (11). In order to enhance this shift, a blended learning course should also increase the interaction between the instructor and students, and also among students. Martyn (12) defined a successful blended model, a model containing the first class face-to-face orientation, weekly online assessment, synchronic chat, asynchronous discussion, E-mail and the last class face-to-face closure along with a controlled final exam.

The bulk of studies on "the necessity for blended learning implication" indicated that the method attracts the attention of many researchers. For instance, in a cumulative study, Sharpe et al. (13) reviewed 300 investigations done on blended e-learning and stated the positive outcomes of blended learning on learning experience of high school mathematics learners. Flexibility on learning, enhanced class learning experiences, and increased learners' cooperation are some of these advantages.

While Sikora and Carroll (14) reported that postsecondary learners studying all of their lessons online were less satisfied of e-learning compared to traditional learning, Dembo (cited in 15) found combination of e-learning and traditional face-to-face learning more attractive. In his review study on effectiveness of computer-based learning, he concluded that when computer-assisted learning is used along with traditional classroom learning, it is more effective than when it is used instead of traditional classroom learning.

On the same line of research, the present study was designed to find the requirements for blended learning implication from teachers' point of view. To achieve this goal, at first, individual and professional characteristics of academic members of Semnan Payam Noor University (PNU) were considered, after which their views about implication of blended learning in the University were gathered, and finally their identified views were analyzed and classified.

\section{Methods}

In the present applied descriptive research, which was carried out during spring of 2016 in Semnan Payam Noor University branches, a questionnaire was administered to determine the attitudes of academic members' views about requirements for blended learning implication.

Participants in this study were 70 academic members, who were randomly selected by the Krejcie and Morgan formula, from among 85 faculty members of Semnan Payam Noor University. The members were spread at 4 branches of Semnan PNU, so in order to specify the sample of the research, stratified random sampling was used. Accordingly, academic members, who were specified as participants in the study, received the questionnaire via an e-mail at the beginning of spring semester, 2016. The inclusion criteria included being of member with academic tenure, who had permanent teaching and participation of Semnan PNU in spring semester of 2016. Exclusion criteria from the study were lack of these conditions. It is important to note that the rate of response in the traditional methods of sending out questionnaires, like personally interviewing the respondents, distributing and receiving of the questionnaires by hand or mailing is higher than dispatch methods through internet and email. In this regard, Schillewaert, Langerak and Duhamel (15) announced the response rate of three times of sending questionnaires by email to be between $22 \%$ and $36 \%$ of the entire questionnaire.

The data was collected by a questionnaire developed by the researcher on the basis of data collection instruments used in similar studies, literature review, and opinions of specialists. The constructed questionnaire was a closed one composed of 25 items about blended learning application, and asked faculty members to rate importance of each item on a scale ranging from 1 to 5 . The scores obtained were deemed as: $1=$ the least important to $5=$ the most important.

To determine questionnaire validity after its first construction, a copy was sent to a group of 15 specialists in elearning. By the use of the Delphi Method, the judgments of experts were distilled and retrieved, and after two iteration Delphi, the final draft of the questionnaire was approved by specialists. Furthermore, to obtain an accurate estimation of questionnaire reliability, the internal consistency of the items was calculated by the Cronbach alpha formula $(\alpha)$. The estimated reliability by SPSS 18 was 0.95 , which indicated the high reliability of the questionnaire. The responses to the questionnaire were imported and analyzed using the SPSS version 18 statistical program. Given the ethical considerations observed in this study, all participants in the study had full knowledge and provided a consent. The demographic information was confidential, 
and a specific code was designated for each participant for future uses of the data.

\section{Results}

According to the results of the studies, when computer-assisted learning is used along with traditional classroom learning, it is more effective than when it is used instead of traditional classroom learning.

Table 1 displays the characteristics of participants in the study. As inferred from Table $1,51.4 \%$ of the participants in the study were female and $48.6 \%$ were male. The age group of " 41 to 50 " and the academic rank of the "Assistant Professor" with 55.7\% and 51.4\%, respectively, had the highest frequency. While most of the academic members (55.7\%) had "Teaching Experience" of 6 to 15 years; 42.9\% of them used internet less than 10 hours a week.

Table 1. Biographical Characteristics of the Academic Members

\begin{tabular}{|c|c|c|c|c|}
\hline Variable & Level & Frequency & Percentile & Mode \\
\hline \multirow{2}{*}{ Gender } & Female & 36 & 51.4 & \multirow{2}{*}{ Female } \\
\hline & Male & 34 & 48.6 & \\
\hline \multirow{4}{*}{ Age } & Less than 30 & 8 & 11.4 & \multirow{4}{*}{ Between 41 to 50} \\
\hline & Between 31 to 40 & 21 & 30 & \\
\hline & Between 41 to 50 & 39 & 55.7 & \\
\hline & More than 51 & 2 & 2.9 & \\
\hline \multirow{3}{*}{ Academic Rank } & Lecturer & 32 & 45.7 & \multirow{3}{*}{ Assistant Professo } \\
\hline & Assistant Professor & 36 & 51.4 & \\
\hline & Associated Professor & 2 & 2.9 & \\
\hline \multirow{4}{*}{$\begin{array}{l}\text { Teaching } \\
\text { Experience }\end{array}$} & Less than 5 years & 17 & 24.3 & \multirow{4}{*}{6 to 15 years } \\
\hline & 6 to 15 years & 39 & 55.7 & \\
\hline & 16 to 25 years & 13 & 18.6 & \\
\hline & More than 25 years & 1 & 1.4 & \\
\hline \multirow{3}{*}{$\begin{array}{l}\text { Average weekly } \\
\text { internet use }\end{array}$} & Less than 10 hours & 30 & 42.9 & \multirow{3}{*}{ Less than 10 hours } \\
\hline & 10 to 20 hours & 23 & 32.9 & \\
\hline & More than 20 hours & 17 & 24.3 & \\
\hline \multirow{3}{*}{$\begin{array}{l}\text { Average weekly } \\
\text { computer use }\end{array}$} & Less than 10 hours & 17 & 24.3 & \multirow{3}{*}{10 to 20 hours } \\
\hline & 10 to 20 hours & 29 & 41.4 & \\
\hline & More than 20 hours & 24 & 34.3 & \\
\hline
\end{tabular}

Questionnaire results are displayed in Table 2.

As it can be inferred from the the the most important requirements for implementing blended learning were "Supporting teachers and students in blended learning research and development ( $R$ and D)" with KR-21 of 0.335 , "Structuring on-line discussion groups for students" with KR-21 of .35 and "Doing summative as well as formative assessment of the instructional content and generating appropriate feedback" with KR-21 of 0.374 .

In order to extract factors underlying requirements of blended learning implication, which were specified by survey conduction, factor analysis was used. Earlier computa- tions showed that the data was appropriate for factor analysis and the necessary conditions for doing factor analysis were met:

Correlation matrix was positively defined, and the determinant was greater than one, KMO of 0.853 , indicated the adequacy of the sample and Bartlett's test was 1390.27 and significance at $1 \%$, showed the variables were appropriately correlated.

A factor analysis with varimax orthogonal rotation was conducted on the data and five factors with specific variances higher than one were extracted. The extracted factors and their characteristics are represented in Table 3.

The highest special variance belonged to the first factor, which accounted for $49.24 \%$ of the variance. Cumulative variance of factors was $72.23 \%$, which indicated the fact that most changes were related to the requirements for blended learning implications and the remaining variance was related to the variances, which were not examined in the present study.

Factor analysis of the requirements for implication of blended learning from teachers' point of view resulted in five factors: "infrastructure, political, professional, organizational, and instructional" requirements. Table 4 illustrated items clustered in each factor with their loadings.

As it can be inferred from the table, nine items were loaded onto the first factor and was named infrastructure requirements; this factor was the most important factor and accounted for $49.24 \%$ of the total variance. Six items were loaded onto the second factor, which was called political requirements and accounted for $7.75 \%$ of the total variance. The third factor with 5 loaded items was called professional requirements. The fourth factor with 3 loaded items was named organizational requirements and the last factor with 2 loaded items was called instructional requirements. Professional, organizational and instructional requirements accounted for $6.29 \%, 4.61 \%$, and $4.34 \%$ of the total variance, respectively. These extracted factors cumulatively accounted for $72.23 \%$ of the total variance, which indicated their effectiveness.

\section{Discussion and Conclusion}

The purpose of the present study was determination, classification, and analysis of requirements for blended learning implication at Semnan Payam Noor University.

Surveying academic members of Semnan PNU showed that $51 \%$ of the teachers were associated professors. Their teaching experiences ranged from 6 to 15 years. Overall, 41\% of teachers spent 20 hours a week on the computer and the average time $43 \%$ of them spent on the internet was less than 10 hours a week. These factors, i.e. "The average 
Table 2. Requirements for Blended Learning Implication

\begin{tabular}{|c|c|c|c|c|}
\hline Rank & Requirement & Mean & SD & KR-21 \\
\hline 1 & Supporting teachers and students in blended learning research and development ( $\mathrm{R}$ and $\mathrm{D}$ ) & 2.67 & 0.89 & 0.33 \\
\hline 2 & Structuring on-line discussion groups for students & 2.90 & 1.03 & 0.35 \\
\hline 3 & Doing summative as well as formative assessment of the instructional content and generating appropriate feedback & 2.55 & 0.95 & 0.37 \\
\hline 4 & Providing access to the internet with sufficient band width & 2.54 & 0.93 & 0.38 \\
\hline 5 & Educating blended learning course designers & 2.80 & 1.09 & 0.39 \\
\hline 6 & Building skills in hybrid communication and live audio-video communication & 3.11 & 1.23 & 0.39 \\
\hline 7 & Providing classes with internet to use on-line facilities & 2.48 & 0.98 & 0.39 \\
\hline 8 & Acceptance of blended learning by managers, academic members, students and clerks & 2.65 & 1.06 & 0.39 \\
\hline 9 & Building skills to use e-mails regularly & 2.47 & 1.00 & 0.40 \\
\hline 10 & Specifying sufficient funds for blended learning implication & 2.41 & 0.98 & 0.40 \\
\hline 11 & Improving managers attitudes about blended learning implication & 2.64 & 1.09 & 0.41 \\
\hline 12 & Improving teachers and students comprehension of blended learning & 2.90 & 1.20 & 0.41 \\
\hline 13 & Buying sufficient computers according to student's number & 2.57 & 1.07 & 0.41 \\
\hline 14 & Applying other distance learning University's successful experiences & 2.71 & 1.14 & 0.42 \\
\hline 15 & Providing students access to accessories, such as scanners and printers & 2.60 & 1.10 & 0.42 \\
\hline 16 & Making policies for designing and timing blended learning courses & 2.72 & 1.16 & 0.42 \\
\hline 17 & Developing advanced search skills based on ESP courses on databases & 2.55 & 1.11 & 0.43 \\
\hline 18 & Applying new tools e.g. PowerPoint for content development & 2.60 & 1.13 & 0.43 \\
\hline 19 & Accessing the computer and high speed internet on the University campus & 2.08 & 0.92 & 0.44 \\
\hline 20 & Motivating teachers and students for a shift from traditional methods of learning towards blended learning & 2.52 & 1.13 & 0.45 \\
\hline 21 & Implementing different instructional methods instead of mere delivering of information & 2.62 & 1.20 & 0.45 \\
\hline 22 & Developing culture of blended learning implication on teachers and students & 2.64 & 1.21 & 0.46 \\
\hline 23 & Creating a blended learning web-site for groups of students & 2.55 & 1.18 & 0.46 \\
\hline 24 & Instructing students based on their needs & 2.50 & 1.16 & 0.46 \\
\hline 25 & Emphasis on learner-based instruction instead of lecturer-based instruction & 2.41 & 1.16 & 0.48 \\
\hline
\end{tabular}

Table 3. Extracted Factors, Specific Variance and Communality Variance

\begin{tabular}{lccc}
\hline Component & Eigenvalue (Total) & \% of Variance & Cumulative \% \\
\hline $\mathbf{1}$ & 12.31 & 49.24 & 49.24 \\
$\mathbf{2}$ & 1.93 & 7.75 & 56.99 \\
$\mathbf{3}$ & 1.57 & 6.29 & 63.28 \\
\hline $\mathbf{4}$ & 1.15 & 4.61 & 67.89 \\
$\mathbf{5}$ & 1.08 & 4.34 & 72.23 \\
\hline
\end{tabular}

time spent on the internet and computer", "teaching experience" and "academic rank" were the most important factors, which Hasheminejad et al. (16) considered affective in changing $61.5 \%$ of teachers views about implication of blended learning.
From PNU academic members' view point, infrastructure requirements were the most preliminary considerations for blended learning implications. In this factor, items of "Specifying sufficient funds for blended learning implication", and "Accessing to computer and high speed internet with sufficient band within University" constituted the most important requirements, which could increase efficiency of blended learning application at Semnan PNU. In the same line of research, "allocation of sufficient funds to blended learning and developing culture of blended learning usage among teachers and students" were the most important requirements for blended learning implication. In the same vein, Oh and Park (17) emphasized that access to a computer, high speed internet and appropriate networks, have positively influenced attitudes of faculty members to use these technologies. Buckley (18) 
Table 4. Clustered Items and Their Loadings

\begin{tabular}{|c|c|c|}
\hline Factor & Items & Loading \\
\hline \multirow{8}{*}{ Infrastructural requirements } & Specifying sufficient funds for blended learning implication & 0.65 \\
\hline & Accessing a computer and high speed internet on the University campus & 0.67 \\
\hline & Providing access to the internet with sufficient band width & 0.77 \\
\hline & Providing classes with the internet to use on-line facilities & 0.56 \\
\hline & Creating a blended learning web-site for groups of students & 0.75 \\
\hline & Providing students access to accessories, such as scanners and printers & 0.83 \\
\hline & Building skills in hybrid communication and live audio-video communication & 0.53 \\
\hline & Structuring on-line discussion groups for students & 0.63 \\
\hline \multirow{6}{*}{ Political Requirements } & Making policies for designing and timing blended learning courses & 0.79 \\
\hline & Supporting teachers and students in blended learning research and development (R and D) & 0.57 \\
\hline & Educating blended learning course designers & 0.52 \\
\hline & Implementing different instructional methods instead of mere delivery of information & 0.61 \\
\hline & Emphasis on learner-based instruction instead of lecturer-based instructions & 0.58 \\
\hline & Instructing students based on their needs & 0.53 \\
\hline \multirow{5}{*}{ Professional Requirements } & Applying other distance learning University's successful experiences & 0.49 \\
\hline & Building skills to use e-mails regularly & 0.73 \\
\hline & Developing advanced search skills based on ESP courses on databases & 0.58 \\
\hline & $\begin{array}{l}\text { Doing summative as well as formative assessment of the instructional content and generating } \\
\text { appropriate feedback }\end{array}$ & 0.73 \\
\hline & Applying new tools ,e.g. PowerPoint for content development & 0.62 \\
\hline \multirow[t]{2}{*}{ Organizational Requirements } & Improving managers' attitudes about blended learning implications & 0.72 \\
\hline & Acceptance of blended learning by managers, academic members, students and clerks & 0.69 \\
\hline \multirow{2}{*}{ Instructional Requirements } & $\begin{array}{l}\text { Motivating teachers and students for a shift from traditional methods of learning towards blended } \\
\text { learning }\end{array}$ & 0.81 \\
\hline & Improving teachers and students comprehension of blended learning & 0.74 \\
\hline
\end{tabular}

believed that easy access to the content would increase learner's satisfactions and would culminate to enhancing the efficiency of blended learning. According to Ajam (19), "teaching skills of interpersonal communication and promoting skills of software/hardware utilization to students and faculty members would enhance their tendency to imply blended learning".

Faculty members considered political requirements as the second important requisite for blended learning implication. Making appropriate policies for planning and scheduling blended learning programs, supporting students and faculty members for research and development on blended learning, and educating specialists in the field of designing blended learning programs are some examples of political requirements. Abdolahzadeh (3) argued that "implication of new learning systems and ICT facilities not only involve learners in electronic environments but also is effective in developing research mood and creative thinking".

Successful implementation of blended learning is subjected to apply the expertise of experts, who have comprehensive knowledge in learning management systems (LMS) and learning content management systems (LCMS). Hence, it is recommended to use experts in LMS and LCMS to plane and implement blended learning in universities.

\section{Footnote}

Conflict of Interest: None declared. 


\section{References}

1. Yerasimou T. Examining interactivity and flow in a blended course to advance blended learning practice. Indiana: University of Indiana; 2010.

2. Garrison DR, Vaughan ND. Blended learning in higher education: Framework, principles and guidelines. San Francisco, CA: Jossey-Bass; 2007

3. Abdolahzadeh A. Comparing efficiency of blended learning with elearning and traditional learning of mathematics among high school first grade male and female students in Ardabil [In Persian]. New Thoughts Educ. 2009;9(2):65-84. doi:10.22051/jontoe.2013.341.

4. Valitan A. Blended learning models Chatsworth: Media Inc; 2002. Available from: http://www.learningcircuits.org.

5. Akkoyunlu B, Soylu MY. 7. A study on students' views on blended learning environment. 2006:43-56.

6. Gould T, editor. Hybrid classes: Maximizing institutional resources and student learning. Proceedings of the 2003 ASCUE Conference. 2016; Myrtle Beach, South Carolina. .

7. Procter $\mathrm{C}$, editor. Blended learning in practice. Conference Proccedingsof Education in Changing Environment. 2003; Salford.

8. Driscoll M. Web-based training: creating e-learning experience. 2nd ed. San Francisco: University of San Francisco; 2002.

9. Allen S, Garrett M. The Extent and Promise of Blended Education in the United States. ; 2009. Blending.

10. Dziuban C, Hartman J, Juge F, Moskal P, Sorg S. In: Handbook of blended learning: Global perspectives, local designs. Bonk CJ, Graham CR, editors. San Francisco, CA: Pfeiffer; 2006.pp.195-208.Blended learning enters the mainstream.
11. Nunan T, George R, McCausland H. Rethinking the ways in which teaching and learning are supported: The flexible learning centre at the University of South Australia. J High Educ Policy Manag. 2000;22(1):85-98. doi: 10.1080/713678130.

12. Martyn M. The hybrid online model: Good practice. Educ Q. 2003;1:18 23.

13. Sharpe R, Benfield G, Roberts G, Francis R. The undergraduate experience of blended e-learning: a review of UK literature and practice. The higher education academy; 2006. pp. 1-103.

14. Sikora AC, Carroll CD. Postsecondary education descriptive analysis reports (NCES 2003-154). Washington, DC: US Government Printing Office; 2002

15. Schillewaert N, Langerak F, Duhamel T. Non-probability sampling for WWW surveys: a comparison of methods. J Market Res Soc. 1998;40(4):307-22.

16. Hasheminejad A, Hoseini M, Hedjazi Y. Analysis of prerequisites of applying blended learning system from perspective of Khuzestan province natural resources and agriculture faculty's members [In Persian]. Iran Engin Educ Q. 2013;15(57):37-50. doi: 10.22047/ijee.2013.2961.

17. Oh E, Park S. How are universities involved in blended instruction? Educ Technol Soc. 2009;12(3):327-42.

18. Buckley KM. Evaluation of classroom-based, Web-enhanced, and Webbased distance learning nutrition courses for undergraduate nursing. J Nurs Educ. 2003;42(8):367-70. [PubMed: 12938900].

19. Ajam AA. The Role of Academic Self-Efficacy and Interpersonal Relations Skills of Students in the evaluation based on Blending Learning. Res Med Educ. 2015;7(1):3-12. doi: 10.18869/acadpub.rme.7.1.3. 